\title{
Los chinos, su identidad y su lugar en la literatura nortina ${ }^{1}$
}

BERnARdo Guerrero JimÉnEZ.

\author{
"Algún día no más te van a hacer pasar un Susto grande, los chinos. Mira \\ que son vengativos ... y comen hasta ratones" \\ (Guillermo Kuenenkampf del cuento "Historia Amarilla").
}

\section{RESUMEN}

La identidad de los chinos construida por los escritores, sobre todo de aquellos vinculados a la generación del 38, es el tema del presente artículo. Ambientada en el Norte Grande de Chile, la literatura comprometida con las luchas obreras, construyó una imagen de la población oriental francamente estereotipada y racista.

\begin{abstract}
The main topic if this article refers to the Chinese identity depicted by the writers, especially by those linked to the generation of 1938. Set in the Norte Grande of Chile, the literature committed with the struggles of the working class built an image of the oriental population frankly stereotyped and racist.
\end{abstract}

1 Este artículo es harte de una investigación mayor que lleva por nombre "Identidad Cultural y Literatura Nortina", financiada por la Dirección cíe Investigación de la Universidad Arturo Prat de Iquique. DI 1498.

\section{Introducción}

Falta la novela de los chinos en la literatura nortina. Falta la novela que se centre en la vida de estos miles de hombres y mujeres que arribaron a estas tierras. No es una deuda tan sólo estética, es también histórica y moral. Una novela que los identifique con sus nombres, su sexo y su historia. Que hable del viaje en barco desde Cantón hasta Pabellón de Pica, hacinados en las bodegas, padeciendo el frío y la humillación, arrojados al mar con cadenas una vez que dejaron de existir (Stewart 1976: 56) Una novela que cuente de su humillación en Pabellón de Pica. Pero además faltan estudios más sistemáticos desde el punto de vista de la antropología, la historia y la sociología. Los chinos, y no está de más repetirlo, constituyen un componente especial en la población del Norte Grande de Chile. Su historia, escrita a retazos y no exenta de prejuicios, es una tarea aún no realizada, pese a los interesantes esfuerzos que en ella se han comprometido. Falta El Libro de los Chinos.

El tema del presente artículo trata acerca de la imagen que en la literatura nortina, es posible encontrar de la población china. Se trata de ver como los literatos, ayudaron a construir una imagen de éstos, por lo general, sesgada y caricaturizada: esto se vuelve aún más relevante en la medida en que notamos que estos autores, construyen una literatura desde una posición de clase, marxista o anarquista con fuertes componentes ilustrados. Las crónicas de principios de siglos, aparecidas en la prensa de la 
época, da cuenta de este fenómeno de segregación que padecieron los chinos ${ }^{2}$. Novelistas y cronistas contribuyeron a legarnos la imagen con la que se definen a los chinos: fumadores, jugadores, misteriosos, etc. Hay un racismo ni siquiera disimulado3.

Para los fines de nuestro análisis hemos seleccionados las novelas Caliche y Los Pampinos de González Zenteno y La Luz viene del Mar de Nicomedes Guzmán. Ambos representantes de la llamada generación del 38. Pero antes de entrar en el tema, esbozaremos una breve historia de los chinos en esta zona.

\section{La presencia china en el sur peruano y norte chileno}

El Iquique de fines del siglo XIX y principios del XX se caracterizó por la presencia de las colonias extranjeras. Estos hombres, mujeres y niños llegaron buscando la tranquilidad y la prosperidad que en sus hogares maternos no encontraron. No todos tuvieron la misma suerte. A todos no le sonrió la diosa fortuna. Pero, de uno u otro modo, echaron raíces e Iquique como siempre les abrió los brazos. Y aquí se quedaron. Las siguientes páginas tienen por objeto caracterizar brevemente los principales rasgos de la Colonia China que animó la vida social, económica, cultural y política de este puerto.

Lo cierto es que tanto las primeras colonias como las segundas han llegado a la ciudad atraídas por cierto esplendor que Iquique se ha encargado de exportar: a fines de siglo pasado, la riqueza guanera; y antes la plata en Huantajaya; a principio del mil novecientos, el desarrollo de la explotación salitrera
2 Representantes de las Colonias Extranjeras, de artesanos y trabajadores de Iquique se han acercado a pedirnos que se organice un "meeting" con el fin de que se pida al Supremo Gobierno tome medidas para que retengan la imigración china a Iquique (17 de julio de 1900).

Inserción

Señor Editor de El Nacional:

Habiendo leído en su acreditado diario de fecha $26 \mathrm{del}$ presente, N’1.130 un artículo de correspondencia de San Francisco de California, bajo el rubro de trabajadores chinos, el cual dice y entre otras cosas ofrece, que en la Compañia Comercial de Centro y Sud América, trata de hacer emigrar por contrato, 30 mil chinos y japoneses para Centro y Sud América y además el Cónsul General del Perú 10 mil para hacerlos repartir en las haciendas del interior. Como testigo ocular y asiático que soy, he tenido ocasión de conocer el maltrato que siempre se ha dado á la colonia asiática en el Perú, cuyos procedimientos son de dominio público.

Me permito hacer por medio de las columnas de El Nacional algunas pequeñas reflexiones que me han surgido para que si llegasen a conocimientos de los incautos que van a caer por desgracia en ese contrato, se pongan á salva-guardia de las fatales consecuencias que puedan sobrevenirles.

Hace largos años que acaudalados comerciantes, armadores de buques y hacendados residentes en el Perú, se han dedicado al famoso y lucrativo negocio de traer asiáticos contratados para dedicarlos á toda clase de trabajos. Estos infelices venian acompañados desde su país y en un punto eran embarcados clandestinamente, porque las leyes del país prohiben la emigración, eran cohechadas las autoridades por los intereses del negocio de enganche y por medio de unas cuantas monedas de oro, cuyo poderoso elemento le facilitaba el camino para efectuar los contrabandos de carne humana, quedando impune el gran delito que cometían los mandarines.

Créame por ahora Señor Editor, que me he permi-tido limitarme a lo expuesto y reservarme aún otros abusos de esos pobres seres humanos que más adelante pondré en conocimiento suyo.

\author{
Atte. \\ Juan García, Iquique Octubre 29 de 1983. \\ Diario El Nacional de Iquique.
}

3 Hay que remetirse a los orígenes de la discriminación. Los más cercano a ello son las teorías de Joseph Arthur Gobineau (1816-82), de quien se dice que si Hitler y sus adláteres hubiesen necesitado apoyo para sus ideas racistas las habrían encontrado en aquél. El fue quien sostuvo que el destino de la civilización estaba determinado por la calidad de la raza, los arios, o blancos era superior a todas las demás, pero si se mezclaba con otras perdía su vitalidad y se corrompía. De esta manera se explica, que este concepto se arraigara entre las clases bajas. No hay que olvidar tampoco que los chilenos temían a la mano de obra barata, por eso a veces habían diferencias con los bolivianos. 
actuó como un poderoso imán frente a los extranjeros que venidos por mar hallaban o creían hallar en Iquique, una suerte de "tierra prometida".

A principios de siglo, leemos de Ugarte Yávar que las colonias más numerosas eran: la peruana, italiana, española, británica, china, austro-húngara, boliviana, alemana, francesa, griega, sueco-noruega, danesa, norteamericana, ecuatoriana y la suiza.

Con el mito de ser empecinados jugadores y de fumadores de opio, los chinos arribaron a tierras iquiqueñas, según sabemos por Perú.

A diferencia de otras colonias, la historia de los chinos pasa por haber sido un contingente humano tratados como esclavos sobre todo en las covaderas de Pabellón de Pica, donde según cuentan, aún es posible hallar cuerpos semienterrados de chinos que fueron duramente tratados en esas faenas.

Lo anterior sirve para graficar el hecho de que siempre la historia de las colonias se ha escrito enfatizando el éxito de éstas, ocultando sus lados oscuros. De allí que siempre se hable de los emigrantes exitosos, y se escondan a los que fracasaron.

Con los chinos, la cosa es diferente, sus dos caras, la del éxito y del fracaso se conocen, quizás más la segunda que la primera. Pero, si hubiese que evaluar ahora la riqueza de los chinos llegados a principio de siglo a lquique, el balance sería exiguo: hay más chinos pobres que ricos.

Pero también hubo chinos prósperos. En el libro de Ugarte Yávar, encontrarnos a uno que logra la cima: Wing Chong Tay y Ca que en Serrano 164 y 166 tenía un Almacén de Abarrotes por Mayor y Menor. Pero este comerciante parece ser uno de los pocos prósperos, sobre todo si lo comparamos a los ingleses, alemanes, españoles e italianos.

\section{El cronista Ugarte Yávar acerca de los chinos dice:}

"La colonia china posee diferentes instituciones de caridad y beneficencia, marchando todas unidas, de acuerdo, y sosteniendo un hospital especial para sus connacionales y un asilo para ancianos y dementes".

"Están dichos establecimientos atendidos debidamente por los facultativos locales y médicos herbolarios chinos".

"Debido á esto han implantado una importante reforma, cual es la de impedir que los chinos pobres lleven á cabo la mendicidad pública, por la cual merece un voto de aplau- sos el principal sostenedor de esta idea, don José M. Reyes, miembro prestijioso de esa colonia".

Esta ha comprado en el Cementerio principal un espacioso terreno donde fabricarán su panteón, que será el más grande de los que cuente aquel" (Ugarte Yávar 1904: 59).

\section{Pabellón de Pica: la esclavitud de los chinos}

Pabellón de Pica es una covadera ubicada a 80 kilómetros al sur de Iquique. Durante el siglo pasado y a comienzos de éste, tuvo una rica actividad producto de la explotación del guano.

Mencionamos Pabellón de Pica, por el rol que en ella jugó el contingente chino. La historia oral local, tiene conciencia clara de que en este lugar los chinos fueron esclavos. Sin embargo, éste es un hecho nunca del todo seguro. Por un lado, los mismos chinos ignoran el hecho y otros arrojan un manto de olvido sobre esta oscura historia. La tradición oral regional consigna el hecho, que en Pabellón de Pica quedan rastros -cadenas por ejemplo- que tiende a confirmar el humillante trato que se le dio a los chinos. Hacia el norte de Pabellón de Pica, existe un monolito con una leyenda alusiva testimoniando el descanso de los chinos. El autor de La Historia de los Puertos Guaneros del Litoral de Tarapacá (hasta 1879) afirma la condición de esclavos de este grupo étnico (Zolezzi 1993: 12).

Las malas condiciones de vida, la discriminación y la humillación, llevaron a muchos chinos a optar por el suicidio, como una alternativa de solución. Este acto estaba incluso legitimado por su mentalidad religiosa:

"Los malos ratos y las humillaciones empujaron al suicidio a muchos chinos de las islas guaneras y de las haciendas, ya sea ahorcándose o ingiriendo una sobredosis de opio. Ellos creían que dejando ese infierno terrestre iban a renacer en China. Los hacendados querían evitar esas muertes embarazosas y con el fin de desalentar los suicidios, obligaban a los otros chinos a quemar el cadáver con el propósito de impedir la 'resurrección' tan deseada" (Lausent-Herrera 1992: 996).

Seguimos a modo de documentación un trabajo de Marcelo Segall "Esclavitud y Tráfico de Culíes en Chile" aparecido en la revista Boletín de la Universidad de Chile $\mathrm{N}^{\circ} 75$ de junio de 1975. Este autor al 
hablar de las diversas formas de esclavitud que hubo en Chile dice.

"Los primeros, los culíes fueron trabajadores chinos sacados de su patria bajo condiciones de esperanza y de engaño, con contratos" (Segall 1967: 52).

El autor cita un diario, El Copiapino publicado por Jotabeche el 19 de mayo de 1853, en él aparece el siguiente aviso:

"Colonos Chinos... la barca Isabel Quintana... debe llegar a Caldera con $120 \ldots$ Todos vienen obligados a ocho años de trabajos forzosos y los hay de diversos oficios... Sus pedidos a don Manuel Chopitea (Segall 1967: 53).

Más adelante, citamos al mismo autor:

"En cuanto a Tarapacá, Perú en la época por una ley de 1849 el gobierno había accedido al propósito de algunos particulares de organizar la inmigración asiática. En 1850-5, aparecieron en el puerto de Iquique los primeros chinos contratados, muchos de los cuales llegaron a ocuparse después en las salitreras. Después de la Guerra (del Pacífico) se dedicaron al comercio en los pueblos de la Pampa y más tarde en Iquique" (Segall 1967: 54).

Segall cita al geólogo Dr. Juan Bruggen quien dice de Pabellón de Pica: "había una población de más de 4.000 obreros, en su mayor parte chinos".

Luego Segall dice:

"Este yacimiento -se refiere a Pabellón de Pica- está centrado en un alto cerro cortado a pique sobre el océano. Sus farellones, roqueríos e islas adyacentes formaban una valiosa covadera. Poseía artillería de costa y una guarnición militar al servicio de la defensa y de la disciplina de los esclavos. Aún ahora, perduran los viejos cañones. También los puentes y túneles que unían las faenas. Además perduran los cadáveres secos de los suicidas que, imposibilitados para huir, saltaban a la libertad entre las rocas. La sal marina, la extrema delgadez y los años los han momificado. Sin embargo, en muchas ocasiones hubo rebelión y la consiguiente represalia. Al castigo de los verdugos inmediatos, a los capataces, se respondió con el fusilamiento y la muerte lenta al sol y encadenados en tierra firme. Lo mismo sucedió en Punta de Lobos, Patache, Huanillos, Paquica y Mejillones" (Segall 1968: 54).

El historiador peruano, Luis Millones Santagadea en su libro Minorías Étnicas en el Perú, nos ilustra acerca de la llegada de los primeros chinos al Perú. Es sabido que desde este país vinieron a Chile y se dispersaron por nuestra geografía. Millones nos responde la pregunta: ¿Qué pasaba en China para que tanta gente huyera de ahí? Citamos:

"La decisión de importar chinos se vio además reforzada por una coyuntura histórica: la rebelión de Taiping. Con este nombre se conoce una dura y prolongada guerra civil que envolvió el sur de China entre los años 1849-1864. El saqueo y la miseria que agotó a las poblaciones del sur y sudoeste chino, precipitó la formación de grupos dispuestos a migrar en busca de mejores condiciones o simplemente sobrevivir. Traficantes localizados a lo largo de la costa sudoeste captaron rápidamente las posibilidades del negocio y procedieron en consecuencia. El mejor exponente de esta situacion fue la colonia portuguesa de Macao, que se convirtió en el primer centro de exportación de trabajadores chinos del siglo XIX" (Millones 1973: 70).

\section{Continúa Millones:}

"Todo esto nos delimita una nueva área de procedencia. Se puede decir que la migración de este período proviene esencialmente de la provincia de Cantón, sin embargo, a los puertos del sudoeste confluyeron gentes de distancias considerables. A juzgar por los dialectos chinos hablados contemporáneos, la migración parece haber descansado en grupos de habla Hakka y Cantonés" (Millones 1973: 70).

Los chinos, han vivido en una situación de extrema pobreza, sin libertad, desarraigados de su cultura y con un trato infrahumano. Dicho lo anterior no debe sorprender que al desatarse la Guerra del Pacífico, se aliaran al ejército chileno, ya que para ellos decir soldado peruano, era decir enemigo. 
Tanto el chileno Segall corno el peruano Millones coinciden en el rol que jugaron los chinos ayudando a los chilenos en su llegada a Lima. Segall nos dice al respecto:

"Cuando la división Lynch tomó Ica, surgió el líder de la libertad culé: Quintín Quintana. Un chino que tomó ese nombre. Especie de Espartaco oriental, orador vibrante y audaz, entusiasmó a sus connacionales 1500 chinos, hombres y mujeres, se enrolaron como auxiliares a las tropas chilenas (Segall 1968: 56).

Complementando lo anterior, Millones nos dice:

"Habiéndose descrito las condiciones en que vivían los coolies, no es de extrañar que al ser roto el control de las haciendas, los chinos se unieron al ejército invasor para usufructuar de la victoria y constituirse en la avanzada para el saqueo de las poblaciones costeras. Los mismos chilenos organizan el ya mencionado batallón Vulcano, encargado de desenterrar minas y torpedos al mando del General Arturo Villarroel (a) Dinamita. A la retaguardia del ejército, un número considerable de chinos acarreaban los víveres y municiones del ejército. Esta situación no era sino el acto reflejo frente al sistema de labor forzado impuesto por los hacendados (Millones 1973: 80).

El día 11 de enero de 1881, poco antes de la batalla de Chorrillos, los chinos se juramentan frente a sus divinidades para enfrentar a los peruanos. La siguiente es una versión atribuida al cirujano chileno A. Queely:

"Ante esa rara trinidad, un chino ofició algo que parecía misa y enseguida procedió a degollar un gallo, símbolo de la guerra, cuya

4 Hay un cuento sobre el particular que alaba la. valentía de los chinos, pero cuando el personaje central Yum-kun-sun, ingresa al ejército, a los días renuncia: "Pol que e muy flejao aplendel a pelial: tiene que tilal bala pelao, hincao, acostao, de toíta laya, y toca tanto la colneta que ya no aguanta pa colel. "Jalalí-talalá!" cole palló. "¿Talalí-talalá!" cole pacá" (Ortiz 1958: 29). En otras palabras no tolera la disciplina del Ejército chileno. sangre depositó en una redoma. Por esa sangre belicosa juraron los chinos ser su deseo y sus votos que las armas de Chile salieran victoriosas, y así se lo pidieron a Kuonglong, con todo respeto, bebiendo enseguida la sangre mezclada con agua. Todos los 658 colonos alcanzaron parte del mistificado líquido. Terminada la ceremonia, el chino Quintín Quintana, jefe elegido por la colonia misma pronunció un largo discurso en que habló de la esclavitud reinante en el Perú y de la próxima libertad e imperio de las leyes comunes" (Lecaros, citado por LausentHerrera 1992: 992).

Sobre el famoso Quintín Quintana, el novelista Daniel Riquelme dice:

"Mucho se ha hablado de la presencia de estos chinos en nuestro campamento. Aun han dicho algunos que formaron un cuerpo de combatientes y que su capataz reconocido, el famoso Quintín Quintana, tuvo grado militar en nuestras filas" (Riquelme 1962: 149).

El ritual de sangre que se le atribuye a los chinos, es así relatado por Riquelme:

Los chinos al llegar a Lurín, detrás de Lynch, celebraron su cónclave; mataron un gallo y mezclaron su sangre con las de sus venas $\mathrm{y}$, después de reconocerse redimidos por el Coronel de una odiosa esclavitud, juraron morir como un solo hombre por la causa de Chile" (Riquelme 1962: 149).

Sirva esta pequeña historia de los chinos para entender mejor aún, la imagen que los otros, en este caso los novelistas, construyen de este grupo étnico.

\section{Los Chinos en las novelas Caliche y Los Pampinos de Gónzalez Zenteno}

Luis Gónzalez Zenteno, pertenece a la generación del 38, junto a Volodia Teilteibom, Andrés Sabella, Nicomedes Guzmán, entre otros. lquiqueño y comunista produjo las novelas Los Pampinos y Caliche, que se ambientan en el norte grande de Chile. En Caliche recrea la crisis económica de los años treinta, y la lucha social en Iquique, en especial la emprendida por los anarquistas. Al decir de Pedro Bravo Elizondo el autor conjuga ficción y realidad de un 
modo que su novela puede llamarse histórica (1998: 25). Por su parte su novela Los pampinos, tiene como tema principal la matanza de La Coruña ocurrida en 1925.

En ambas novelas los chinos, ocupan un lugar marginal y estigmatizado. Así, por ejemplo:

"Por cierto que aquel lenocinio de asiáticos no tenía nada de agradable y había que apretarse la nariz cuando se cruzaba su umbral. Se evadían del interior las dulzarronas emanaciones del opio y la transpiración china, hedionda a té y a tabaco. Tras los cortinajes de canutillos de abalorios que cubrían las puertas, tras las muselinas de las ventanas, se movían las sombras suaves, de largas y sabias manos y reptaba una música asordinada, propicia al sueño" (González 1954: 117) $)^{5}$.

Con respecto al consumo de opio, este mismo autor plantea:

"El opio lo había tomado en sus brazos poderosos y paseaba en andas por el inundo. Iba sobre el estupefaciente como un hijo de Alá en su alfombra mágica, disfrutando de las bellezas de la tierra, de sus montañas, de sus desiertos, de sus inviernos, de sus primave-

5 En otro lugar define a los chinos: "El negocio de Tay Wong estaba repleto de un público bullicioso, delante del cual los chinos plomizos, de piel lustrosa, saltaban con su agilidad característica (González Zenteno 1954: 12).

6 Sobre los efectos del consumo de opio, la novela Los Pampinos dice: "Tay integraba el grupo. De espaldas en la cama, se sumergía en el pasado con la serena entereza del que se ha liberado cíe su cárcel corporal y es ya sólo un áreo pensamiento. En lenta sucesión desfilaban los recuerdos y un goce íntimo le crispó los labios delante de una escena memorable. Era en Cantón. Rayaban el cielo gris, bandadas de golondrinas. Emigrantes de todas las latitudes. Alas del mundo. El, de pie frente a un pupitre, retocaba un cuadro. ¿Podía llamarse cuadro? ¿Cabía el arte en este subterfugio? Rió complacido. Era un dólar, un dólar falso que acababa de reproducir magistralmente del original" (González Zenteno 1956: 52). ras, de sus ciudades, de sus habitantes. Lágrimas y risas. Miserias y grandezas. El eterno juego (González 1956: 52).

\section{Los Chinos en La luz, viene del Mar de Nicomedes Guzman}

El escritor Nicomedes Guzmán, en su novela La Luz viene del mar, ambientada en el barrio El Colorado y en la pampa salitrera, es el único que en sus páginas le otorga a los chinos identidad, historia y destino, aunque como se verá reforzando el estigma. Uno de sus personajes, trágicos en su destino como se verá más adelante, Sergio Lin, es definido de este modo:

"Hiéretico, comenzaba ya a esta hora de la tarde a saborear la influencia del opio, que todo lo realiza con sus sólidos y dulces sopores" (Guzmán 1963: 37).

El personaje sirve para tratar el tema de la llegada de los chinos al norte del país.

"La llegada de Sergio Lin al país remontábase por sobre largos años. Años que pasaron dejando el regusto de profundas angustias superadas. Quizá Sergio Lin reprimiera sus recuerdos. Mas lo cierto era que la vida lo trasladó a estos lares en uno de esos enganches que el capital organizara para la explotación de las covaderas norteñas. Contrato de un dólar por año de servicios, he aquí el El Dorado que lo sugestionó" (Guzmán 1963: 37) .

Fiel a la realidad de la época, el novelista constata la desgraciada vida en las guaneras, y le agrega el elemento de la rebelión, por vía del escape:

"Sorprendióse en su error a tiempo. Y Sergio Lin huyó del infierno de la extracción del guano, después que, con unos compañeros, descubriera un cementerio de chinos detrás de un caserío derruido. El espanto y el terror, que lo mismo aniquilan las fuerzas como la engrandecen, insuflaron en los ánimos del oriental tales ansias de libertad que desertó sin mayores preámbulos de las heroicas legiones de los trabajadores del guano" (Guzmán 1963: 37).

La imagen del chino con su coleta lo amarraba 
demasiado a su condición de oriental. Lin decide:

"...su primera determinación fue cortarse la coleta. Así rapado y silencioso logró, al través de algunos años pacientes y sufridos, una pequeña plaza en un negocio de Pozo Almonte" (Guzmán 1963: 38).

Ya radicado en Iquique, en el barrió El Colorado el novelista describe la vida cotidiana de este personaje:

"Las tardes del Chino Lin limitaban, ya cerrados los candados de la noche, en un plato de arroz y en una ritual taza de té. Luego, limpio y de severo chaqué, fijo sobre su cabeza rapada el tarro de pelo, abríanse para él las puertas del Restaurante El Palacio de Cristal. Aquí había opio, juego y mujeres magníficas; más, hembras atrayentes y sugestionantes, entre las que sobresalía la presencia enervante de Fresia Zamudio..." (Guzmán 1963: 38).

Pero también los define:

"Ellos, los orientales, eran así: trajinaban, se acostaban, volvían a sonar en el piso sus pasos cautelosos, cocinaban huevos, riñones, comían arroz y, luego estaban una vez más en la cama. Se diría que los chinos sólo vivían de noche al amparo del misterio de las sombras laminadas por las lámparas vacilantes" (Guzmán 1963: 83).

\section{Y agrega:}

"De día, herméticos a todo lo que no fuera razón de comercio, expresaban una parsimonia y una limitación de palabras en que ellos

7 El modo que los novelistas hacen hablar a los chinos, es también indicativo del estigma. Su mal hablar el español, es además generador de identidad aunque sea negativa. Jorge Inostroza y Guillermo Bascuñán compusieron "Los Chinos de Cerro Azul", (Al 7" de Línea), una canción interpretada por Los Cuatro Cuartos, en la que relata el aporte de los orientales a la conquista de Lima, al mando de Patricio Lynch "A comerle los liñones con palillos de marfil". Lo singular es que los chinos llegan antes que Lynch a la ciudad. no existían, recluidos en un mundo ciego, alrededor del cual la imaginación del populacho creaba historias, leyendas inverosímiles y siempre bellas " (Guzmán 1963: 83) .

Con una vida subterránea, que se desliza por la noche:

Para los chinos la noche era la vida. Incontaminados de lo que no les perteneciera en costumbres, hacían su existencia nocherniega con ese júbilo seco y enigmático que apenas se suponía tras los tabiques y cuya versión daban los pasos, las voces apresuradas y casi inauditas, el ajetreo precursor del guiso deseado, el silencio mismo en cuyos resquicios había siempre algún paso como de rata o vinchuca recién hartada" (Guzmán 1963: 84).

"El Chino asumía la actitud de permanente defensa que siempre adoptan los de su raza frente a quienes respetan como a sus superiores. En realidad, había en Sergio Lin hacia Basilio Cholakis una veneración casi mística: le admiraba como a un ser espléndido y excepcional" (Guzmán 1963: 173).

Amarillo, la palabra opera como signo clasificatorio de identidad, pero además amantes del dinero:

"Puso en las manos del Chino un billete grueso que el amarillo atrapó casi con júbilo" (Guzmán 1963: 179).

Por otro lado, el novelista no escapa a su condición de varón. Pinta la imagen de la mujer china con rasgos diminutos; tiene nombre y se llama Clementina Hiut.

"Ella iba con su esposo hermético y reposado como buen oriental, entrando al negocio, circunspecta, hierática, a cortos pasitos" (Guzmán 1963: 228).

Pero es una chinita, nótese el uso del diminutivo, Eudocio el personaje la piensa como "ratonzuela deliciosa" (Guzmán 1963: 228). Es una mujer adúltera que engaña a su marido. La causa de tal conducta está en:

"Hernán Win no hacel má que caliño. ¿Besal, besal, y tocal no má! ¿Pol esto quelelte a ti!" (Guzmán 1963: 232) ${ }^{7}$. 
Si el Chino Sergio Lin, arrancó de las guaneras para hallar su libertad; su signo trágico habría de manifestarse en su desdichada vida amorosa. Al suicidarse, manifiesta su destino trágico. La tragedia, en las guaneras o en el amor representan una línea de continuidad con el ethos oriental.

"El Chino Lin se ahorcó con unas mechas de lámparas que remató hace unos días... Se colgó de unas de las vigas de su propio cuarto... El tenía sus amores, señora Sofía ..., y la mujer que él más quería se le fue anoche..., al parecer ... ¿Las cosas!" (Guzmán 1963: 316).

La mala suerte de los orientales en estos parajes, se constituye en otro tema de identidad:

"Se mata recién el Chino Lin... Y como si esto fuera poco, la china Clementina Hiut..., bueno, usted sabe, la esposa del Chino Win, se pierde un par de días con Eudocio, el hijo de la Señora Irene.. ¿Qué tne dice usted? Ahora, el chino Win va a retobar a su china para mandarla de nuevo al Oriente, de donde la trajo..." (Guzmán 1963: 318).

\section{Conclusiones}

Sin nombres, mencionados simplemente como "chinos", "amarillos" o "descendientes del imperio celeste", entre otros, los orientales carecen de sexo, identidad, historia y biografía. Y cuando uno de ellos logra tener un nombre sólo es para caricaturizar aún más su condición. Retratados como comerciantes ambulantes y sobre todo como fumadores de opio, los chinos concentran para la opinión pública de ese entonces, los epítetos de "misteriosos y faltos de higiene". Con excepción de la novela de Nicomedes Guzmán los chinos aparecen con historia y destino, aunque trágicos.
El suicidio del chino Lin representa muy bien, la imagen que escritores "progresistas" ayudaron a construir de este grupo. La muerte aparece como la única forma de evitar el sufrimiento.

La pregunta que surge al tenor de las páginas precedentes es ¿por qué estos escritores que profesaron la ideología comunista y/o anarquistas, e hicieron gala de un internacionalismo proletario, y que honestamente denunciaron los atropellos que sufrían los pampinos, construyeron una imagen e identidad tan negativa como estigmatizante de los chinos, más aún si éstos fueron tan explotados como los obreros? No hay una sola respuesta para esta pregunta. No sólo los chinos padecieron el estigma, sino que también los indios y las mujeres. Estos dos últimos son vistos como "bárbaros" o "débiles".

Una posible respuesta se encuentre en la mentalidad ilustrada de la época que veía a la sociedad tensada en la disputa entre barbarie y civilización. El pensamiento social no pudo sustraerse a este influjo. Ubicó a los obreros como la élite redentora de la humanidad. El proletariado como clase social, remitida a su lugar en el proceso de producción no reconocía como sus hermanos en la explotación, a los chinos, indios y mujeres ya que éstos se desenvolvían en labores de servicios: comerciantes, arrieros, labores de casa, etc.

Casi al finalizar el siglo, y con un proceso de renovación de la novela nortina, con otras claves y otras estéticas como por ejemplo, La Reina Isabel cantaba rancheras de Hernán Rivera o Muriendo por la dulce patria mía de Roberto Castillo Sandoval, el relato -de cualquier forma que asuma- debería reconciliarse con los chinos, parte integrante de nuestra identidad cultural.

Los chinos no sólo han dejado huella en su dolor, sino que también en su generosidad. El año 1910, un 18 de Septiembre, los chinos en Iquique, deciden en un gesto que los retrata de cuerpo entero, obsequiar los terrenos donde se construyó la Escuela Elemental de Hombres $\mathrm{N}^{\circ} 6$, la Centenario ${ }^{8}$. Los miles de niños que allí hemos estudiado, al cantar el himno chino, intentamos devolverles la sonrisa que nuestros antepasados le robaron.

En proceso de saldar cuenta con nuestros antepasados, la literatura tiene una deuda con esos hombres y mujeres que ayudaron a cultivar el "desierto más árido del mundo".
8 El investigador iquiqueño Pedro Bravo Elizondo destaca además la generosidad de los chinos al apoyar instituciones deportivas y culturales (1983: 72), que aún perviven. 


\section{BIBLIOGRAFIA}

BAHAMONDE, Mario; Antología del Cuento Nortino. Univer1966 sidad de Chile. Departamento de Extensión Universitaria. Antofagasta.

BRAVO ELIZONDO, Pedro; Los "enganchados" en la era 1983 del salitre. Ediciones Literarura Americana Reunida. Madrid.

BRAVO ELIZONDO, Pedro; GUERRERO, Bernardo; Historia $1998 \quad y$ Ficción Literaria sobre el Ciclo del Salitre en Chile. Sin editar. Iquique.

CHOU, Diego L.; "Los chinos en Chile. Vida socio-económica y 1996 cultural". En: Encuentros en Catay. $\mathbf{N}^{\circ}$ 10. Departamento de Lengua y Literatura Españolas. Universidad Fujen-Taipei.

GONZALEZ ZENTENO, Luis; Caliche. Editorial Nascimiento 1954 Santiago.

GONZALEZ ZENTENO, Luis; Los Pampinos Editorial Prensa 1956 Latinoamericana. Santiago.

GUERRERO, Bernardo; Del Chumbeque a la Zofri. La identidad 1996 cultural de los iquiqueños. Centro de Investigación de la Realidad del Norte. Iquique.

GUERRERO, Bernardo; "Iquique era una villa grande y hermosa: Iquique en la pluma de escritores y geógrafos". En: Revista de Ciencias Sociales. $\mathrm{N}^{\circ} 5$. Universidad Arturo Prat. Iquique. pp 112.

GUZMAN, Nicomedes; La luz viene del mar. Zig-Zag. Santiago. 1963

MILlONES, Luis; Minorías Etnicas en el Perú. Pontificia Uni$1973 \quad$ versidad Católica del Perú. Lima.
NUÑEZ, Jorge; Los Chinos en Chile. Algunos Antecedentes $\mathrm{s} / \mathrm{f}$ Históricos. Sin editar.

ORTIZ, Luis; "Talali-Talala" en: Cuentos de Guerra Chile1958 nos. Editorial del Nuevo Extremo. Santiago. pp. 25-32

UGARTE Y. Juan de Dios; Iquique. Desde su fundación hasta 1904 nuestros días. Iquique.

LAUSENT-HERRERA; "La cristianización de los chinos en el 1992 Perú: integración, sumisión y resistencia". En Bulletín de l' Institut Français d' Etudes Andines. Tomo 21. Nㅜ 3. Lima. pp. 977-1008.

LOPEZ L, Fernando; Letras de Molde. Iquique 1907. 1907

RIQUELME, Daniel; Bajo la tienda. Recuerdos de la campaña 1968 al Perú y Bolivia. 1879-1884. Zig-Zag. Santiago.

SEGALL, Marcelo "Esclavitud y Tráfico de Culíes en Chile". En Boletín de la Universidad de Chile $\mathrm{N}^{\circ}$ 75. Junio. Santiago. pp. 52-61.

STEWART, Watt; La Servidumbre China en el Perú. 1976 Mosca Azul Editores. Lima.

ZOLEZZI, Mario; "Historia de los Puertos Guaneros del Litoral de Tarapaca (Hasta 1879)". Iquique. Centro de Investigación de la Realidad del Norte. Cuaderno de Investigación Social $\mathrm{N}^{\circ} 34$. 
